\title{
Amino Acid Profiles and Cytotoxicity of Mirabilis expansa (Ruiz and Pav.) Standl.; Baseline Data for A Rare Indigenous Andean Crop
}

\author{
M Kritzer Van Zant ${ }^{1 *}$, WJ Banz ${ }^{2}$, HB Chai ${ }^{3}$, Apgar $^{2}$, DA Lightfoot ${ }^{1}$ \\ ${ }^{1}$ Department of Plant, Soil and Agricultural Systems, Southern Illinois University, Carbondale, IL-62901-4415, USA \\ ${ }^{2}$ Department of Animal Science, Food, and Nutrition, Southern Illinois University, Carbondale, IL 62901-4317, USA \\ ${ }^{3}$ Division of Medicinal Chemistry and Pharmacognosy, College of Pharmacy, The Ohio State University, Columbus, OH 43210 , \\ USA
}

Received Date: 06 February, 2019; Accepted Date: 18 February 2019; Published Date: 02 April 2019.

*Corresponding author: M Kritzer Van Zant, Department of Plant, Soil and Agricultural Systems, Southern Illinois University, Carbondale, IL-62901-4415, USA. Email: mkvzant@gmail.com

\section{Abstract}

Rare, indigenous, Andean Mirabilis expansa (Ruiz and Pav.) Standl. (Nyctaginaceae), has promise as a new, green, climate change resistant crop for arid areas. Leaves and stems were used as fodder, roots and rhizomes for human food. Two crop varieties of $M$. expansa were grown in lysimeter sand plots in southern Illinois. Herbage and root profiles were compared to amino acid profiles for other crops, eggs and milk. Quinoa, wheat, soybeans, and skim milk had greater percentages than $M$. expansa of all individual amino acids reported. However, M. expansa samples have all essential amino acids, and matched or exceeded other sources examined for percentages of crude and total protein. Total protein per $100 \mathrm{~g}$ dry sample averaged $5.98 \mathrm{~g}$ in roots and $24.43 \mathrm{~g}$ in leaves. Cytotoxic, non-volatile micro molecules were not detected in methanol extracts of $M$. expansa assayed against HT-29 colon cancer cells. Processing should improve palatability and food safety for this crop.

Keywords: Amino acid profiles; Cytotoxicity; Drought resistance; Mirabilis expansa; Nyctaginaceae

\section{Introduction}

\section{Potential of an Ancient Crop}

High protein content has been reported for the ancient, rare, Andean crop, M. expansa (Ruiz and Pav) Standl. (Nyctaginaceae) in both roots used for human consumption, and in leaves primarily used for animal fodder [1-4]. By 1984, plant foods provided $65 \%$ per capita of protein worldwide and $32 \%$ in North America [5]. Amino acid balance is important when developing feed and feeding regiments for livestock, with requirements varying for each animal species [6]. Essential amino acids for protein production in humans [510] and livestock [10] are HIS (histidine), ISO (isoleucine), LEU (leucine), LYS (lysine), MET (methionine), PHE (phenylalanine), THR (threonine), TRP (tryptophan), and VAL (valine).

Wild relatives of the Nyctaginaceae gave rise to high protein seed crops including amaranth (Amaranthus caudatus L. (Amaranthaceae)) and Andean quinoa (Chenopodium quinoa Wild. (Chenopodiaceae)) [11-12]. Amino acid profiles for both are compared below to M. expansa, along with soy and eggs. Also compared are several true grains from the grass family, including wheat, corn, Barley (Bar), millet, and rye. Though commonly eaten, these true grains contain glutinous compounds which can trigger allergies or food sensitivities [13]. Legumes including soy, though high in commonly limiting lysine, are not readily digested by some individuals [14]. Excess protein intake resulting from over consumption of meat and protein supplements underlie multiple health problems [14]. Therefore, alternative protein sources such as M. expansa are needed.

Roca and Izquierdo [15] discuss the need to bring scarce indigenous Andean crops back into common cultivation, including mauka ( $M$. expansa), to improve diets for economically challenged Andean families. Bolivian mauka was reported as having $7 \%$ protein content in below ground plant parts and $17 \%$ in the foliage, while Peruvian M. expansa 
from Cajamarca was claimed to have $4-5 \%$ protein $[\mathbf{1 , 1 6}$. These lower percentages were probably in roots, based on our own results. Though charts compiled from the literature compare information on minerals and other nutrients for $M$. expansa [17], all sources examined lacked information on individual amino acids. Low in sodium, M. expansa is high in calcium and phosphorous, often deficient in Andean diets [16]. However, M. expansa calcium may be bound up in nonbio-available calcium oxalate, at least before processing. Malnutrition is more than a matter of lacking sufficient calories or lethal starvation. Protein or mineral deficiencies can lead to ill health and social problems [14]. In addition, some persons are unable or unwilling to consume protein from animals. Thus, each additional plant source of essential amino acids has the potential to greatly improve quality of life and health for many individuals, especially growing children.

Drought resistance and the avoidance of transgenics [19] are important reasons to look at alternative crops, including $M$. expansa. Andean soils are well known to be volcanic in origin. Some Andean soils drain well; others required terracing and other engineering efforts to improve drainage for crops [20, 21]. Irregular rain cycles occur in many parts of the Andean range, with drought a frequent problem for farmers. Andean paramo regions, cold highland desert scrubland ecosystems, have conditions in which $M$. expansa thrives. $M$. expansa has been described as able to produce as much food as a good potato field, "above the potato line" (Carlos Ochoa, personal communication 1997). M. expansa grown at lower altitudes requires less water than potatoes, and at higher altitudes has little competition with other food crops. If $M$. expansa proves to be non-invasive, or at least controllable, it should be especially valuable in arid ecosystems primarily dependent on ocean mist or cloud moisture, including other tropical mountain regions $[\mathbf{1 8 , 2 2}]$. $M$. expansa has the potential to grow any place where it receives sufficient drainage in its root zone, and its minimal requirements are met. It will take effort and resources to establish $M$. expansa as a modern crop. As with many crops, methods are needed to separate its edible components, and remove or moderate anti-nutrients.

\section{Safety Issues for Consumption of $M$. expansa}

Traditionally, most mature $M$. expansa plants were dug up, then either hung to dry, or re-buried within straw-lined pits, arranged in stacks with roots at right angles to each other, for at least eight days prior to consumption $[\mathbf{1 , 1 7 , 1 8 ]}$. Curing may simply have been intended to sweeten roots $[\mathbf{1 , 2 , 1 6 , 2 3 ]}$, as was practiced for other Andean crops [24]. Drying may also have been intended for preservation. Our food safety concerns for $M$. expansa first arose when learning of indigenous preparation practices.

In addition, all parts of $M$. expansa plants were observed on microscope slides to be thickly permeated with long, needle-like raphide crystals, made of calcium oxalate. Raphides persist even in three-hundred-year old herbarium specimens. Raphides act as swords on the single-celled linings of insect digestive tracts. Calcium oxalate is the primary substance forming kidney stones as it is highly insoluble [25]. Calcium oxalate makes leaves of cultivated rhubarb (Rheumrhabarbarum L. (Polygonaceae)) and Andean oca (Oxalis tuberosa Molina (Oxalidaceae)) indigestible, and gives a tangy taste to chard, beet greens and spinach. Calcium oxalate crystals [25] are present in various amounts in most foods, and are prevalent in quinoa seeds. Quinoa requires cooking or sprouting to increase palatability, which may affect the crystals. Calcium oxalate's insolubility makes its calcium non-bio-available. Cooking and/or simultaneously ingesting alkalizing foods and/or certain probiotic bacteria, could convert calcium oxalate to a bio-available form of calcium. These bacteria have pathways for converting calcium oxalate to soluble, and therefore bio-available, $\mathrm{Ca}^{2+}$ [26-28], potentially increasing the crop's nutritional value. Traditional fermentation of $M$. expansa, of which we found a single report [17], may have had this effect, though drying prior to use was most often reported $[\mathbf{1 7 , 1 8}]$. As raphides remain intact and extremely dense in dried leaves, roots, and stems, it is unlikely that the drying of $M$. expansa by indigenous people, altered calcium oxalate on its own. However, it may be that bacterial action on roots, while they sat in straw-lined pits, resulted in the breaking of calcium oxalate bonds.

M. expansa plants are thought to have insect, virus, and fungal resistance due to unique proteins in the root epidermis $[\mathbf{3 , 2 9}, 30-34]$. Flores, Vivanco, Vepachedu and their associates, identified a unique Class I ribosome inhibitor in root extracts of $M$. expansa, including extracts made from plants grown from var. ' $L$ ' seed provided by Kritzer Van Zant [33]. Class I ribosome inhibitors are thought to only affect insects, not mammals (J.M. Vivanco, personal communication, 2008). Vivanco said that he found active protein in samples of $M$. expansa including material shipped to him from Peru, which had taken weeks post-harvest to be delivered. Therefore, that delay did not seem to affect either the ribosome inhibiting protein or the calcium oxalate crystals. It remained to be tested if drying the plants prior to consumption altered food safety or medicinal activity. It was also thought possible that $M$. expansa contains active defensive micro-molecules, as well as enzyme inhibitors and raphides. Perhaps, micro-molecules were being altered after eight days or more of curing the plant.

\section{Cytotoxicity Testing and Amino Acid Profiles of the Crop}

Methanol extracts were made [35] from short-season southern Illinois grown $M$. expansa, and submitted for cytotoxicity testing with the HT-29 colon cancer cell line $[36,37]$ to initiate investigation of micro-molecules. HT-29 cells have often been used for initial pharmaceutical screening of natural products because of their extremely high sensitivity to toxic compounds [36,37]. Results from the cytotoxicity testing are given below as exploratory food safety evidence for M. expansa.

To find out whether reports of high protein in $M$. expansa would hold up in laboratory tests, samples of cultivated varieties ' $L$ ' and ' $T$ ' grown in southern Illinois [18,22] were analyzed for their amino acid contents. Data is presented for 
each amino acid tested, crude protein and total protein. These are the first amino acid profiles for the crop, species, genus and family. Amino acid profiles for $M$. expansa are also compared below to published amino acid profiles for the previously mentioned protein sources, along with alfalfa, beet and cassava (Manihot esculenta Crantz (Euphorbiaceae)) $[6,11,12,38-41]$.

\section{Materials and Methods}

\section{Cultivation and Production of M. expansa Samples}

Plant material for the amino acid profiles and cytotoxicity study was grown in constructed sand plots at the Horticultural Research Center at Southern Illinois University (SIU-C), then harvested and lyophilized [18,22]. M. expansa is unusual in its ability to store nutrients above ground in stems, below ground in enlarged stems called rhizomes, and in roots. These structures become packed with starch in $M$. expansa, obscuring anatomical differences between them. Therefore, for most samples, the above/below ground separation was generalized as leaf and root, respectively. There was also one var. ' $T$ ' stem sample.

Soil amendments used to grow the crop were similar though not identical for the two varieties [18,22]. Growth of material is also discussed in Supporting Information (SI) under SI Materials and Methods. Each single data point assayed represents more than one plant from more than one plot which received the same soil amendment, or more than one plant grown exclusively in the greenhouse, with a single exception. Only one plant was used for one of the two var. ' $T$ root samples (Table 2; SI Tables 1 and 2).

\section{M. expansa Profiles}

Standardized amino acid testing was used for profiling $M$. expansa, through a flat-fee service for agronomists at the University of Missouri-Columbia (UM-C). Var. ' $L$ ' leaf and root were profiled separately to total eight var. ' $L$ ' samples. Four var. ' $T$ ' samples were also profiled, including leaf, root, and stem. Lyophilized materials were stored at $-80^{\circ} \mathrm{c}$ until weighed for amino acid profiling and the cytotoxicity assay. Methods utilized for the amino acid profiling at UM-C are given in Horwitz and Latimer [42]. Three separate analyses were performed for a complete profile. TRP, and together both MET and CYS, underwent separate hydrolysis steps from the other amino acids. Each of the three analyses had the same internal standards. Results were given as percent dry weight per $100 \mathrm{~g}$ of sample (Tables 1 and 2; SI Table 1). In addition, there is a table with $M$. expansa individual amino acid data given as ratios of crude protein (SI Table 2). Samples from the two varieties, and above and below ground grown portions of each, were presented separately in the tables, or as a range of numbers instead of as averages in the text. This was because of discrepancies between years, soil amendments, and varieties. Additional details on the amino acid profiling are in SI.

Comparison of $M$. expansa with Other Protein Sources 3 | Advances in Nutrition and Food Science, Volume 2019, Issue 01
Protein sources from the literature used for comparison with $M$. expansa were standardized to g/100 g dry weight of sample. Listed by date of publication, these protein sources used for comparison were: egg [38]; corn2 [39]; wheat, soybean, and skimmed milk [11,12]; field quinoa seeds and hydroponic quinoa leaves and seeds [12]; corn gdhA+ and corn gdhA- [6]; five cassava samples and also their average [40]; additional corn samples (DDGS, DDGHP, Germ, Glutfeed (Gluten feed), Glutmeal (Gluten meal), GrnYD (Green YD), GrnHN (Green HN), GrnHO (Green HO), GrnLP (Green LP), and Hominy (Hom), also Bar, beet, egg, flax and millet [41] (SI Table 1).

Information on decisions to exclude some profile sources is in SI. In addition, the lysine/crude protein ratios for $M$. expansa (SI Table 2) were included in the discussion below, relative to a few sources reporting ratio data. There was not sufficient matched $M$. expansa data in the amino acid profiles for meaningful statistics.

\section{Cytotoxicity Testing of $M$. expansa Methanol Extractions}

\section{Cytotoxicity Sample Extraction}

Methanol extracts were made, then samples rotoevaporated. An electric coffee grinder was used to grind lyophilized material for the methanol extractions. Ground material and methanol were combined in $50 \mathrm{ml}$ Falcon $^{\mathrm{TM}}$ tubes. Most samples, including all eight samples from field grown material, were extracted at a ratio of $20 \mathrm{~g}$ of lyophilized plant material to $25 \mathrm{ml}$ of methanol per single sample. Each ground sample was left in methanol for overnight extraction in a $-20^{\circ} \mathrm{C}$ freezer. Each day, samples covered in methanol on the previous day, were centrifuged at $4000 \mathrm{~g}$ (Eppendorf 5810R) at $4{ }^{\circ} \mathrm{C}$ for $10 \mathrm{~min}$. Thus, each sample was extracted three times.

Extracted samples of var. ' $L$ ', submitted for cytotoxicity testing were: LS1-leaf and stem; LOL1-fresh leaf and stem; L8L1-eight-day dried leaf and stem; L0R1-fresh root; and L8R1-eight-day dried root. Extracted samples of var. ' $T$ ' submitted for cytotoxicity testing were: TOL1-fresh leaf and stem; T8L1-eight-day dried leaf and stem; T0R1-fresh root; and T8R1-eight-day dried root. These abbreviations for sample names are used below (Table 3).

\section{Roto-evaporation of Methanol for Cytotoxicity Samples}

Methanol was removed from the samples utilizing a modified extraction protocol from Jones \& Kinghorn [35]. The rotary evaporator (roto-vap) extractor (Buchi New Castle, DE) utilized a cold finger to return the methanol gas to liquid. Each day's methanol extract was rotated in a round bottom flask for 5-13 hours on the roto-vap, to remove the methanol. Evaporation time varied as the amount of $\mathrm{MeOH}$ recovered after filtration through cotton sheeting varied, and room temperature and relative humidity contributed to the speed of methanol loss. Extracted materials from each sample for each 
of the three days of extractions were combined into the same vial after methanol removal so only one sample was submitted to the cell assay from each ground-up sample. Vials were stored at $-20^{\circ} \mathrm{C}$ between additions and when not in use.

\section{Drying Of Cytotoxicity Samples}

After the third day's addition of evaporated material for a given sample, each vial was slowly dried under a gentle stream of nitrogen at room temperature to remove residual methanol. Nitrogen drying typically took at least eight hours for most samples and usually about 12 hours. It is doubtful that any highly volatile compounds, if present, survived such lengthy drying. After methanol removal, and again after nitrogen gas drying, samples were stored at $-20^{\circ} \mathrm{C}$. After nitrogen drying, samples still appeared damp or oily. Therefore, all nitrogen dried samples were re-lyophilized simultaneously for $24 \mathrm{hrs}$. Samples were then weighed into aliquots in brown glass containers, sealed with fresh Parafilm ${ }^{\mathrm{TM}}$, and shipped together at room temperature to Ohio for the cytotoxicity assay.

\section{Cytotoxicity Testing of $M$. expansa}

Lyophilized extracted samples were tested on 22 June 2010, in highly sensitive HT-29 colon cancer cell cytotoxic assay, using a modified protocol [37]. Five samples were submitted for var. ' $L$ ', and four more for var. ' $T$ ' (Table 3). The drug Paciltaxil, a known active for the assay, was used as a positive control. Control wells received $10 \mu \mathrm{L}$ of $10 \%(\mathrm{v} / \mathrm{v})$ DMSO as a negative control. Data analysis followed Likhitwitayawuid et al. [37]. Absorbance was measured at 515 $\mathrm{nm}$ with a micro plate reader (Bio-Tek $\mu$ Quant, Winooski, $\mathrm{VT})$. $\mathrm{ED}_{50}$ values of the serial dilutions of the test samples were calculated with non-linear regression analysis (AISN Software, Inc., Mapleton, OR) (Table 3).

\section{Results and Discussion}

\section{Amino Acid Profiles and Comparison to Other Protein Sources}

Results of the amino acid profiling for each indispensable amino acid, CRDP and TOTP follow for each $M$. expansa sample tested (Tables 1 and 2; SI Table 1). Data is presented in the text from highest to lowest percentage for each category. Means, medians and modes are given for all samples for which each amino acid, total protein, or crude protein were reported (SI Table 1). M. expansa amino acid percentages including both indispensable and dispensable amino acids, together with those for sources reported from the literature, are presented in full (SI Table 1).

\begin{tabular}{|c|c|c|c|c|c|c|c|c|c|}
\hline & Plant part & Leaf & Leaf & Leaf & Leaf & Root & Root & Root & Root \\
\hline & Treatment & Zero & 3P & 1P\&3S & $5 S$ & 1P\&3S & Zero & $5 S$ & $3 \mathbf{P}$ \\
\hline & $\begin{array}{c}\text { Plant } \\
\text { \#s }\end{array}$ & $\begin{array}{c}3 \mathrm{~L}+ \\
5 \mathrm{~L}\end{array}$ & $\begin{array}{l}9 \mathrm{~L}+ \\
14 \mathrm{~L}\end{array}$ & $\begin{array}{c}\text { 17L+ } \\
22 \mathrm{~L}\end{array}$ & $\begin{array}{c}26 \mathrm{~L}+ \\
30 \mathrm{~L}\end{array}$ & $\begin{array}{c}\text { 17L+ } \\
22 \mathrm{~L}\end{array}$ & $\begin{array}{c}3 \mathrm{~L}+ \\
5 \mathrm{~L}\end{array}$ & $\begin{array}{c}26 \mathrm{~L}+ \\
30 \mathrm{~L}\end{array}$ & $\begin{array}{l}9 \mathrm{~L}+ \\
14 \mathrm{~L}\end{array}$ \\
\hline \multirow{10}{*}{$\begin{array}{l}\text { Amino } \\
\text { Acids }\end{array}$} & ARG & 1.30 & 1.28 & 1.36 & 1.35 & 0.24 & 0.21 & 0.23 & 0.26 \\
\hline & HIS & 0.54 & 0.53 & 0.57 & 0.56 & 0.13 & 0.12 & 0.13 & 0.13 \\
\hline & ISO & 1.14 & 1.11 & 1.20 & 1.19 & 0.25 & 0.23 & 0.26 & 0.27 \\
\hline & LEU & 1.98 & 1.90 & 2.03 & 2.05 & 0.38 & 0.35 & 0.36 & 0.39 \\
\hline & LYS & 1.43 & 1.41 & 1.47 & 1.49 & 0.38 & 0.34 & 0.38 & 0.39 \\
\hline & MET & 0.49 & 0.46 & 0.51 & 0.50 & 0.11 & 0.10 & 0.10 & 0.11 \\
\hline & PHE & 1.41 & 1.36 & 1.46 & 1.44 & 0.24 & 0.22 & 0.25 & 0.27 \\
\hline & THR & 1.04 & 1.01 & 1.04 & 1.09 & 0.27 & 0.25 & 0.26 & 0.30 \\
\hline & TRP & 0.30 & 0.31 & 0.32 & 0.28 & 0.05 & 0.05 & 0.06 & 0.05 \\
\hline & VAL & 1.37 & 1.34 & 1.44 & 1.44 & 0.31 & 0.28 & 0.31 & 0.32 \\
\hline \multirow[t]{2}{*}{ Totals } & CRDP* & 28.71 & 28.70 & 29.43 & 30.66 & 9.31 & 7.88 & 9.11 & 9.25 \\
\hline & TOTP & 23.69 & 22.84 & 24.43 & 24.25 & 5.98 & 5.34 & 5.55 & 5.94 \\
\hline \multicolumn{10}{|c|}{$\begin{array}{l}\text { Notes: } \\
\text { *Percentage N X 6.25; } \\
\text { Sample \#5 received January 7, 2010; } \\
\text { W/W\%= grams per } 100 \text { grams of sample; } \\
\text { Values standardized, plants combined prior to profiling; } \\
\text { Results are expressed on an "as is" basis unless otherwise indicated; } \\
\text { Therefore, these are percentages of the total dry weight. }\end{array}$} \\
\hline
\end{tabular}

Table 1: M. expansa indispensable amino acid profiles var. 'L'. 


\begin{tabular}{|c|c|c|c|c|c|}
\hline & Plant part & Root & Leaf & Stem & Root+ \\
\hline & Treatment & $4 \% \mathrm{~S}$ & NA & NA & $2 \% \mathrm{P}$ \\
\hline & Plant & T25+ & Grnhs & Grnhs & T21 \\
\hline & $\# \mathbf{s}$ & T17 & & & \\
\hline \multirow{10}{*}{$\begin{array}{l}\text { Amino } \\
\text { Acids }\end{array}$} & ARG & 0.26 & 0.99 & 0.27 & 0.28 \\
\hline & HIS & 0.14 & 0.42 & 0.15 & 0.2 \\
\hline & ISO & 0.25 & 0.84 & 0.26 & 0.31 \\
\hline & LEU & 0.41 & 1.49 & 0.45 & 0.47 \\
\hline & LYS & 0.38 & 1.25 & 0.41 & 0.49 \\
\hline & MET & 0.1 & 0.34 & 0.11 & 0.14 \\
\hline & PHE & 0.25 & 0.92 & 0.29 & 0.29 \\
\hline & THR & 0.26 & 0.83 & 0.32 & 0.31 \\
\hline & TRP & 0.05 & 0.15 & 0.04 & 0.08 \\
\hline & $\overline{\text { VAL }}$ & 0.32 & 1.01 & 0.33 & 0.38 \\
\hline \multirow[t]{2}{*}{ Totals } & CRDP* & 8.94 & 22.52 & 8.78 & 13.91 \\
\hline & TOTP & 5.98 & 16.8 & 5.99 & 7.76 \\
\hline \multicolumn{6}{|c|}{$\begin{array}{l}\text { Abbreviation: } \\
\text { Grnhs = greenhouse-grown. }\end{array}$} \\
\hline \multicolumn{6}{|c|}{$\begin{array}{l}\text { Notes: } \\
\text { *Percentage N X 6.25; } \\
\text { Sample \#5 received January 7, 2010; } \\
\text { W/W\% = grams per } 100 \text { grams of sample; } \\
\text { Values standardized, plants combined prior to profiling; } \\
\text { Results are expressed on an "as is" basis unless otherwise Indicated; } \\
\text { Therefore, these are percentages of the total dry weight. }\end{array}$} \\
\hline
\end{tabular}

Table 2: $M$. expansa indispensable amino acid profiles var. ' $T$ '

\section{Comparison of M. expansa to Other Crops-Indispensable Amino Acids}

For percent ARG, highest to lowest for $M$. expansa were: var. ' $T$ ' leaf 0.99 ; var. ' $T$ ' stem 0.27 ; var. ' $T$ ' root $0.26-0.28$; and var. ' $L$ ' root $0.21-0.2$. Therefore, for percent ARG all $M$. expansa samples exceeded beet, flax, alfalfa, Bar and millet, also corn samples GrnYD, Glutmeal, DDGHP, DDGS, Germ, Glutfeed, Hom, GrnHN, GrnHO and GrnLP, and cassava root samples \#Avg6, \#ICB300-Dp, \#4, and \#10.

For percent HIS, highest to lowest for $M$. expansa were: var. ' $L$ ' leaf $0.53-0.57$; var. ' $T$ ' leaf 0.42 ; var. ' $T$ ' root 0.14 0.20 ; var. ' $T$ ' stem 0.15 ; and var. ' $L$ ' root $0.12-0.13$. Therefore, for percent HIS all $M$. expansa samples exceeded flax, alfalfa, Bar, beet and millet, also corn samples DDGHP, DDGS, Glutfeed, Germ, Hom, GrnHO, GrnHN, GrnLP and GrnYD, and cassava root samples \#ICB300-Dp, \#Avg6, \#ICB300-3, \#10 and \#4.

For percent ISO, highest to lowest for $M$. expansa were: var. ' $L$ ' leaf 1.11-1.20; var. ' $T$ ' leaf 0.84 ; var. ' $T$ ' root 0.25 0.31 ; var. ' $L$ ' root $0.23-0.27$; and var. ' $T$ ' stem 0.26 . Therefore, for percent ISO, all $M$. expansa samples exceeded corn samples DDGHP, DDGS, Glutfeed and Germ, and there was a great deal of overlap among $M$. expansa samples with the remaining sources.

For LEU highest to lowest for $M$. expansa were: var. ' $L$ ' leaf 1.90-2.05; var. ' $T$ ' leaf 1.49; var. ' $T$ ' root 0.41-0.47; var. ' $T$ ' stem 0.45 ; and var. ' $L$ ' root $0.35-0.39$. Therefore, for percent LEU, all $M$. expansa samples exceeded flax, millet, alfalfa, Bar and beet, also corn samples DDGS, Glutfeed, GrnHN, GrnLP, Germ, GrnHO, GrnYD, Hom and DDGHP, and all six cassava root samples.

For percent LYS, highest to lowest for $M$. expansa were: var. ' $L$ ' leaf 1.41-1.49; var. ' $T$ ' leaf 1.25 ; var. ' $T$ ' root 0.38 0.49 ; var. ' $T$ ' stem 0.41 ; and var. ' $L$ ' root $0.34-0.39$. Therefore, for percent LYS, all M. expansa samples exceeded egg [41], flax, alfalfa, beet, Bar, and millet, also corns gdhA+, gdhA-, corn2, DDGHP, Glutmeal, Germ, DDGS, Glutfeed, Hom, GrnLP, GrnHO, GrnHN and GrnYD, and all six cassava root samples.

For percent MET, highest to lowest for $M$. expansa were: var. ' $L$ ' leaf $0.46-0.51$; var. ' $T$ ' leaf 0.34 ; var. ' $T$ ' root 0.10 0.14 ; var. ' $T$ ' stem 0.11 ; and var. ' $L$ ' root $0.10-0.11$. Therefore, for percent MET, all M. expansa samples exceeded flax, alfalfa, Bar, beet, corns DDGHP, DDGS, Glutfeed, 
Germ, GrnHN, GrnHO, GrnLP, Hom and GrnYD, and all six cassava root samples.

For percent PHE, highest to lowest for $M$. expansa were: var. ' $L$ ' leaf 1.36-1.46; var. ' $T$ ' leaf 0.92 ; var. ' $T$ ' stem 0.29 ; var. ' $T$ ' root $0.25-0.29$; and var. ' $L$ ' root $0.22-0.27$. Therefore, for percent PHE, all $M$. expansa samples exceeded flax, alfalfa, millet, Bar, beet, also corns DDGS, Glutfeed, Germ, Hom and GrnLP, and cassava roots \#9, \#Avg6, \#10, and \#4.

For percent THR highest to lowest for $M$. expansa were: var. ' $L$ ' leaf 1.01-1.09; var. ' $T$ ' leaf 0.83 ; var. ' $T$ ' stem 0.32 ; var. ' $T$ ' root $0.26-0.31$; and var. ' $L$ ' root $0.25-0.30$. Therefore, for percent THR, all M. expansa samples exceeded egg [41], flax, alfalfa, millet, beet, Bar, corns Glutmeal, DDGS, Glutfeed, DDGHP, Germ, Hom, GrnHN, GrnHO, GrnLP and GrnYD, and all six cassava root samples.

For percent TRP, highest to lowest for $M$. expansa were: var. ' $L$ ' leaf $0.28-0.32$; var. ' $T$ ' leaf 0.15 ; var. ' $T$ ' root 0.05 0.08 ; var. ' $L$ ' root $0.05-0.06$; and var. ' $T$ ' stem 0.04 . Therefore, for percent TRP, all M. expansa samples exceeded alfalfa, millet, Bar, beet, also corns Glutmeal, DDGHP, DDGS, Germ, GrnLP, Hom, Glutfeed, GrnHN, GrnHO, GrnLP and GrnYD. However, the percent of TRP was unusual for $M$. expansa indispensable amino acids as it does not exceed the amount in any of the six cassava samples.

For VAL highest to lowest for $M$. expansa were: var. ' $L$ ' leaf 1.34-1.44; var. ' $T$ ' leaf 1.01; var. ' $T$ ' root 0.32-0.38; var. ' $T$ ' stem 0.33 ; and var. ' $L$ ' root $0.28-0.32$. Therefore, for percent VAL, all M. expansa samples exceeded flax, egg [38], alfalfa, millet, Bar, beet, also corns Glutmeal, DDGHP, DDGS, Glutfeed, Germ, Hom, GrnLP, GrnHN and GrnYD, and all six cassava root samples.

For percent of every individually considered indispensable amino acid, skim milk, all three quinoa samples, soybean, and wheat, exceeded all M. expansa samples. Additionally, and only for percent of MET, one egg sample [38] also exceeded all M. expansa samples. However, all $M$. expansa samples exceeded corns DDGS, Germ and GrnLP, for all ten indispensable amino acids. For percent of nine indispensable amino acids all $M$. expansa samples exceeded corn Hom, alfalfa, beet, and Bar, with ISO the sole exception. $M$. expansa, closely planted in an experiment in the Andes, produced significantly higher fodder yields than improved alfalfa grown in California [17-18]. All M. expansa samples exceeded flax and millet, for percent of eight indispensable amino acids. ISO was higher in flax and millet, TRP in flax, and TYR in millet, than in $M$. expansa. All $M$. expansa samples also exceeded eight indispensable amino acids for corns GrnYD, DDGHP and GrnHN. Seven of the same indispensable amino acids, ARG, LEU, LYS, MET, THR, TRP and VAL were exceeded by $M$. expansa for corns GrnYD, DDGHP and GrnHN. In addition, all M. expansa samples exceeded corn $\mathrm{GrnHO}$ for percent of six indispensable amino acids, and corns Glutmeal and Glutfeed for percent of five indispensable amino acids each. Mirabilis expansa exceeded the remaining sources examined for fewer than five indispensable amino acids (SI Table 1).

For indispensable amino acids in cassava roots, $M$. expansa exceeded cassavas \#4, \#10, and \#Avg6 for eight indispensable amino acids each, cassava \#ICB300-Dp for seven indispensable amino acids, and cassavas \#9 and \#ICB300-3 for six indispensable amino acids each. $M$. expansa samples overlapped all remaining sources examined, for percent of individual indispensable amino acids. Amounts of overlap varied for particular M. expansa samples (SI Table 1).

Percentages of dispensable amino acids had more complex patterns than indispensable amino acids for $M$. expansa, relative to the other sources, though both varieties were competitive for some dispensable amino acids (SI Table 1).

\section{Comparison of M. expansa to Other Crops-Totals}

TOTP was not reported in the literature for any corn sample other than corn2, nor for alfalfa, Bar, beet, egg [41], flax or millet. It is unclear if TOTP values from the literature include all amino acids for every sample, or only included the amino acids assayed. Therefore, it was only possible to compare TOTP to those few samples for which it was reported. CRDP is not reported for any of the cassava root samples, gdhA+ and gdhA- corn, or egg [34]. Numbers for TOTP and CRDP in $M$. expansa were encouraging. For percent TOTP, highest to lowest were: var. ' $L$ ' leaf 22.84 24.43; var. ' $T$ ' leaf 16.8; var. ' $T$ ' root 5.98-7.76; var. ' $T$ ' stem 5.99; and var. ' $L$ ' root 5.34-5.98. Therefore, the quantity of TOTP in all $M$. expansa samples was higher than in all other sources reported, including skim milk, wheat, soybean and the three quinoa samples, which had consistently exceeded $M$. expansa for percent of individual indispensable amino acids. $M$. expansa leaves of both varieties also exceeded egg [38] for TOTP. M. expansa leaves had more than three times the TOTP of any other source. SI Results and Discussion contains a detailed comparison of M. expansa TOTP to those of these other protein sources.

CRDP is generally considered an estimate of TOTP and therefore another way to compare $M$. expansa with other protein sources. CRDP is more likely to be a uniform measurement than TOTP. This is because when assessing TOTP, there is some loss of protein due to degradation during hydrolysis, though this degradation occurs in a fairly consistent manner for matching samples. For percent CRDP, highest to lowest were: var. ' $L$ ' leaf 28.70-30.66; var. ' $T$ ' leaf 22.52; var. ' $T$ ' root 8.94-13.91; var. ' $L$ ' root 7.88-9.31; and var. ' $T$ ' stem 8.78 . Therefore, for percentage per $100 \mathrm{~g}$ of CRDP, all M. expansa leaf samples exceeded all other protein sources presented here by more than double. Var. ' $L$ ' leaves exceeded CRDP in all other sources more than three-fold. Also for percentage CRDP, M. expansa root samples overlapped with skim milk and soybean. In addition, for percentage CRDP, all M. expansa samples exceeded wheat, all quinoa samples, egg [41], flax, alfalfa, Bar, millet, beet, and 
all reported corn samples. SI Results and Discussion contains a detailed comparison of $M$. expansa CRDP to those of these other protein sources.

Hemp seeds (Cannabis sativa L.) are known for their high protein content, having about $24 \%$ crude protein [43]. For dry samples that would be $\sim 24 \mathrm{~g} / 100 \mathrm{~g}$ for hemp, while $M$. expansa leaves range from $22.52-30.66 \mathrm{~g} / 100 \mathrm{~g}$.

Though, this comparison of $M$. expansa with other protein sources is preliminary, and not statistically based, it makes a very strong case for $M$. expansa being much higher than all other samples with which it was compared, for leaves and roots in TOTP, leaves in CRDP, and competitive or higher for roots in CRDP for both varieties. In addition, for the percentages of every indispensable amino acid, CRDP and TOTP, leaves of both varieties exceeded roots of both varieties and also exceeded var. ' $T$ ' stem. These numbers are particularly impressive as the crop has not to date been bred with modern methods to improve amino acid profiles.

$M$. expansa var. ' $T$ ' enlarged stem is usually closer to roots of both varieties than to leaves of either, for percentages of each amino acid and of CRDP and TOTP. This is most likely related to $M$. expansa's use of both roots and stems for storage. Var. ' $L$ ' leaves had a higher percentage of most amino acids and more TOTP and CRDP than var. ' $T$ ' leaves. The reverse was true for roots. Var. ' $T$ ' roots had more of every indispensable amino acid than var. ' $L$ ' roots. Var. ' $T$ ' roots also overlapped with, or exceeded, var. ' $L$ ' roots for TOTP and CRDP. It is tempting therefore to say var. ' $L$ ' is better for forage. However, each variety had a different degree of response to excess water $[\mathbf{1 8 , 2 2}]$.

No cassava data was reported for ISO, TRP, or CRDP [40]. All M. expansa samples exceeded cassava roots for percentages of indispensable LEU, LYS, MET, PHE, THR, and VAL [40]. All M. expansa leaf samples also greatly exceeded all cassava samples for ARG and HIS [40]. Var. ' $L$ ' roots exceeded most cassava samples for all reported indispensable amino acids. Var. ' $T$ ' roots and stem exceeded all cassava samples for indispensable HIS, LEU, LYS, MET, PHE, THR, and VAL, and approached or exceeded most cassava samples for ARG [40]. Cassava leaves had been reported to have about $7 \%$ protein on the 2016 CGIAR website which no longer carries that information [44]. Based on the CGIAR information; it appeared that $M$. expansa leaves of both varieties greatly exceed cassava leaves for TOTP. However, Nassar and Marques [45] reported 22.73 to $32.58 \%$ crude protein for cassava leaves, along with their high cyanide content, and the need to breed low cyanide cassava varieties. Until low cyanide varieties of cassava are developed, or methods for separating cyanide from cassava protein, cassava leaf protein cannot be utilized for food or fodder. Additional considerations also exist for $M$. expansa relative to cassava. Roots of improved cassava varieties are still relatively poor protein sources. However, cassava roots are a major source of starch world-wide. Cassava is grown as a cash crop for export in regions where many people need to consume more of the cassava they grow, or use the same land to grow other crops for their own consumption. Much of the world depends on cassava for human food and animal feed, particularly in the tropics. M. expansa not only has a competitive amino acid profile but simultaneously produces large amounts of quality starch, on arid soils, while additionally providing high quality forage. Most cassava is grown on wet soils.

In all reported cases, leaves of $M$. expansa exceeded all true grain samples examined, except wheat, for percentages of all indispensable amino acids. Dispensable HLY, HPR, LAN, and ORN were not reported here from any sources other than $M$. expansa, itself lacking LAN altogether. In addition, dispensable TAU was not reported for any true grain including wheat. $M$. expansa roots and var. ' $T$ ' stem, were competitive with true grains for indispensable amino acids. $M$. expansa exceeded all true grains considered for CRDP where data was available for comparison.

\section{Cytotoxicity Screening with HT-29 Colon Cancer Cells}

\begin{tabular}{|c|c|c|c|c|}
\hline & & Variety & $\begin{array}{c}\text { Sample } \\
\text { description }\end{array}$ & $\begin{array}{c}\text { HT-29 } \\
\text { LD50 } \\
\end{array}$ \\
\hline \multirow{9}{*}{ Sample \# } & LS1 & var. ' $L$ ' & leaf/stem & $>20$ \\
\hline & LOL1 & var. ' $L$ ' & fresh leaf/stem & $>20$ \\
\hline & L8L1 & var. ' $L$ ' & 8-day leaf/stem & $>20$ \\
\hline & L0R1 & var. ' $L$ ' & fresh root & $>20$ \\
\hline & L8R1 & var. ' $L$ ' & 8-day root & $>20$ \\
\hline & T0L1 & var. ' $T$ ' & fresh leaf/stem & $>20$ \\
\hline & T8L1 & var. ' $T$ ' & 8-day leaf/stem & $>20$ \\
\hline & T0R1 & var. ' $T$ ' & fresh root & $>20$ \\
\hline & T8R1 & var. ' $T$ ' & 8-day root & $>20$ \\
\hline Control & Paclitaxel & & active control & 0.001 \\
\hline
\end{tabular}




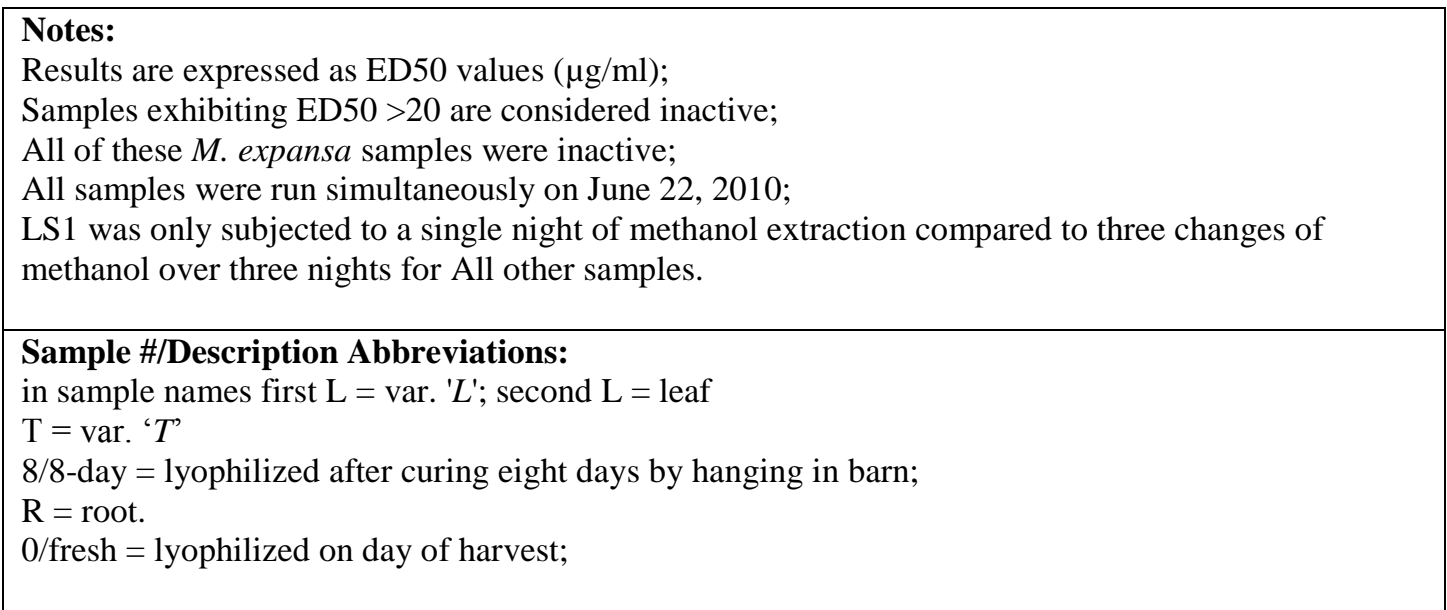

Table 3: Cytotoxicity testing of $M$. expansa methanol extracts against HT-29 colon cancer.

Results of the cytotoxicity screening are expressed as $\mathrm{ED}_{50}$ values $(\mu \mathrm{g} / \mathrm{ml})$ (Table 3). Samples exhibiting ED50 >20 are considered inactive. Cytotoxicity testing against HT-29 colon cancer gave negative results for $M$. expansa for every sample tested. Though cytotoxicity testing of these extracts only addressed short-season grown material in clones of two Andean varieties grown in southern Illinois, the results consistently gave reassurance that there were no toxic nonvolatile micro-molecules in that material, a cautious step in the right direction for the safety of $M$. expansa for food and forage. This cytotoxicity testing did not address questions regarding the safety of the Class I ribosome inhibitor and also did not negate concerns over the crop's high oxalic acid content. However, both issues might be addressed through processing. Though no difference was seen in the southern Illinois summer grown samples, neither barn dried first, nor lyophilized fresh, this may change in roots grown for longer periods. Lyophilization itself may also have caused the same changes as air drying does, especially in the extremely arid Andes. In the Andes, roots are typically grown for 1-2 yrs before harvest [17]. Testing is needed, to determine which processing methods are best, and/or how to extract the protein and starch, and how safe $M$. expansa forage is for livestock.

\section{Conclusions}

Domesticated $M$. expansa varieties ' $L$ ' and ' $T$ ' appear to be living protein machines. More information is needed on the safe consumption of $M$. expansa for both humans and livestock. New conservation efforts are needed for existing varieties and wild types, including the breeding of new varieties for survival in the face of climate and other change in the Andes, and for use in arid areas around the world. It would be helpful if extant crop varieties and wild species could be conserved at more sites, including conservation botanical gardens outside of South America. This would serve as a hedge against loss of this rare crop due to rapid climate change and other factors. Remediation of oxalates should be explored, including fermentation with bacteria having pathways to break oxalate bonds, mechanical separation, and/or enzymatic digestion, and to separate protein and starch from oxalates.

Developing new crop varieties, may improve palatability and safety for M. expansa consumption, and improve the crop in other ways. However, it should also be considered that reducing the presence of oxalates and/or the amount of the enzyme inhibiting protein, may also result in the loss of natural protection for the crop while it is being grown and stored. That may mean it will be better to focus on oxalate remediation during post-harvest processing than on overly reducing the oxalate load through breeding. Care should also be taken, as for any crop, not to create crop varieties that become widely invasive. In the case of $M$. expansa, this might result if its limiting factor of extreme sensitivity to too much water in the root zone were to be strongly reduced. The extremely high potential for the crop, as a source of large amounts of complete protein, quality starch, and forage, with little water on marginal soils $[\mathbf{1 8 , 2 2}]$, makes these worthwhile tasks. Comparing amino acid profiles for $M$. expansa with those of other sources gives a baseline for future research and increases understanding of $M$. expansa's value as a protein source for human food, animal feed, and fodder. Results from research on $M$. expansa illustrate the value of further examination of neglected crops.

\section{Abbreviations and Nomenclature}

Indispensable amino acids (IAAs): arginine (ARG); histidine (HIS); isoleucine (ISO); leucine (LEU); lysine (LYS); methionine (MET); phenylalanine (PHE); threonine (THR); tryptophan (TRP); valine (VAL). Dispensable amino acids: alanine (ALA); aspartic acid (ASP);cysteine (CYS); glutamic acid (GLU); glycine (GLY); hydroxyproline (HPR); hydroxylysine (HLY); lanthionine (LAN); ornithine (ORN); proline (PRO); serine (SER); taurine (TAU); tyrosine (TYR). Total amino acids: crude protein (CRDP); total protein (TOTP). Amino acid profile samples from the literature use coded abbreviations from the sources so are only partially explained here. Glutfeed (Gluten feed), Glutmeal (Gluten 
meal), GrnYD (Green YD), GrnHN (Green HN), GrnHO (Green HO), GrnLP (Green LP); hominy (Hom); barley (Bar). Cytotoxicity sample names used in (Table 3) from var. ' $L$ ' are: LS-leaf and stem; LS1Aq-leaf and stem fraction aqueous resuspension; LOL1-fresh leaf and stem; L8L1-eight-day dried leaf and stem; L0R1-fresh root; and L8R1-eight-day dried root. Cytotoxicity sample names used in Table 3 from var. ' $T$ ' are: T0L1-fresh leaf and stem; T8L1-eight-day dried leaf and stem; T0R1-fresh root; and T8R1-eight-day dried root.

\section{Supporting Information (SI)}

SI consists of additional text, the table of all amino acid profile results for $M$. expansa and from the literature (SI Table 1), and the same amino acid data transformed as ratios of crude protein (SI Table 2). In addition to reduced versions of (SI Tables 1) and (SI Tables 2), links are given within table notes to download Excel versions of each table, under SI Results and Discussion, below.

Additional text includes both SI Materials and Methods and SI Results and Discussion. SI Materials and Methods consist of more detailed notes on the extractions, drying of extracts, and the cytotoxicity assay. SI Results and Discussion includes text descriptions for each indispensable amino acid, CRDP, and TOTP, here including the percent value for each source compared, listed from highest to lowest. All $M$. expansa and literature profile amino acid percentages, including those for dispensable amino acids, are presented (SI Table 1). In addition, for $M$. expansa, percent of each amino acid, including dispensable amino acids, are given as a ratio of CRDP (SI Table 2). In SI Conclusions, there is additional discussion of the results of the cytotoxicity screening, and additional general considerations are added to those, given in Conclusions, above.

\section{SI Materials and Methods}

\section{Cultivation and Production of M. expansa Samples}

Var. ' $L$ ' harvested and lyophilized in 2008 , consisted of material grown in, and combined from, several outdoor plots amended with either $5 \%$ steer manure, $3 \%$ peat, a mixture of $1 \%$ peat with $3 \%$ steer manure, and an all sand control. Var. ' $T$ ' samples were harvested and lyophilized in 2009 . Var. ' $T$ ' root samples were from two plants grown in plots originally amended with $4 \%$ steer manure, and root with some attached underground enlarged rhizome from a single root grown in 2 $\%$ peat. The single stem sample, from var. ' $T$ ', had become somewhat enlarged with stored starch. This stem sample was from exclusively greenhouse-grown stock plants. Two var. ' $T$ ' leaf samples, from the same exclusively greenhouse-grown plants, included attached enlarged stems, and leaf without stem, and were also profiled separately. Numbers of samples depended on combinations of soil treatments, and survivorship from those plots.

\section{Comparison of M. expansa with Other Protein Sources}

Data from the literature for quinoa [12], all corn samples except corn2 [39], wheat and milk [7], originally selected for comparison, could not be standardized to the amino acid data from the $M$. expansa profiles. Therefore, these sources were dropped from the comparison and replaced with several from the USB/US [41] swine data charts. Nassar and Sousa's [40] cassava data was used to replace cassava data from Schlick and Bubenheim [12]. M. expansa's profile data came from lyophilized material from individual plants, combined for each level of soil amendment prior to profiling. Therefore, each data point was measured individually and is not an average of results.

\section{General Considerations for the Cytotoxicity Testing of $M$. expansa}

Comparison was also made of cured and uncured material for the cytotoxicity test, with no obvious differences emerging from the negative data. Though variables for all samples were imperfectly matched between varieties, it was the best match possible with material available at that time. For amino acid profiling, lyophilized samples were cut into small pieces with a heavy scissors, weighed to a minimum of five grams each, then packed into Falcon ${ }^{\mathrm{TM}}$ tubes, and shipped to University of Missouri (UM). In the profile assay, cation exchange chromatography (CIEC-HPLC) was combined with postcolumn ninhydrin derivation and quantization.

\section{Cytotoxicity Sample Extraction}

LS1 and its derivative, LS1Aq, are briefly described above. After completing the practice run which resulted in samples LS1 and LS1Aq (initially named LR1), Dr. Chai was consulted and a decision made to extract the remaining field grown samples at half the concentration of sample to methanol. This reduction was to reduce time needed to evaporate methanol. The improved ratio was $20 \mathrm{~g}$ of lyophilized plant material to $25 \mathrm{ml}$ of methanol for each subsequent extraction resulting in a single sample. This improved ratio was used to produce all eight samples submitted for cytotoxicity testing from field grown material.

Supernatant from each methanol extraction was strained daily by pouring through non-sterile cotton sheeting, with a few $\mathrm{ml}$ of methanol squirted onto the cotton filter to wash through trapped supernatant. Supernatant was subjected to methanol removal each extraction day, and the pellet resuspended in fresh methanol for further extraction. This was repeated once per day, for a total of three times per sample. Extracted methanol from each of the three days was refrigerated until transported over ice to another building for methanol removal. To get better coverage of ground up material with methanol, Falcon tubes were tightly capped and laid on their sides in the refrigerator. Each morning of the extraction period, tubes were shaken up, and then spun down. Altogether, material from ten var. ' $T$ ', and 15 var. ' $L$ ' plants were included in the cytotoxicity testing. 


\section{Roto-evaporation of Methanol for Cytotoxicity Samples}

During rotation, the flask was kept slightly immersed in a water bath at $40^{\circ} \mathrm{c}$ or cooler. As the water bath on the rotary evaporator did not have a properly functioning thermostat, there was considerable fluctuation in temperature as methanol evaporation proceeded. Ice and/or ice water were frequently added back to the water bath to lower temperatures when they began to climb out of range. The speed at which the flask spun was manually slowed or sped up as needed, which changed the amount of energy from rotation and thus heat both inside and outside the flask. On the advice of John Haddock, styrofoam peanuts were added to the water in which the round bottom flask was rotating, to help make the temperature more even, and allowed the heating dial to be positioned at a lower temperature. Methanol, removed and purified on the roto-vap each day for each sample, was included along with fresh methanol to re-suspend the same sample on the following days, until each pellet was discarded.

TOR1 was the only root sample not to have lyophilized material which had been grown in each of the different plot types combined for that variety prior to grinding and extraction. T0R1 did not include material from a one percent peat and three percent steer manure plot, as it had been used up in the amino acid profiling. A single day's evaporation of L0R1 was heated to $\sim 50^{\circ} \mathrm{C}$, which was a sufficiently high temperature to create a visible change. The other two days of LOR1 extraction were combined with the overheated material, then processing continued in the normal manner.

Production and development of the protocols while extracting and evaporating LS1 and LS1Aq are detailed in Kritzer Van Zant's dissertation [22], and include more details on modifications of drying times after roto-evaporation, and information on protocol adjustments due to bands of white and yellow crystals that adhered to the inside of the extraction vial during roto-evaporation. At least some of the crystal bands were suspected of being calcium oxalate. Their handling may offer a clue on how to mechanically separate oxalate crystals from protein and starch.

\section{Drying of Cytotoxicity Samples}

Some samples were dried with nitrogen gas a second time on the day following initial drying, then returned to the freezer. This was done because there appeared to still be water in the samples. After $12 \mathrm{hrs}$ of nitrogen drying, samples dried to a tarry-oily often still liquid substance, which had either a light golden or light green cast, and varied in clarity. In general, leaf/stem material was more likely to be greenish, probably due to the presence of chlorophyll. After all the samples were extracted, the wet appearance of most of each extract was unsatisfactory, as it was unclear if any methanol was still trapped in the samples. Prior to re-lyophilization, each sample was homogenized with a metal stirring rod, and vials were individually covered with para-film. Holes were poked into the film with a pin cleaned with ethanol. On the advice of Jim Persinger, glass lyophilization chambers were wrapped in aluminum foil to limit exposure of the samples to UV light.

This second lyophilization gave the extracted material a fluffy, crystalline and fully dry appearance. This fluffy material stuck to the inside of the vials. Fully dried material often varied in color, in patches in each sample, and appeared spun like cotton candy containing tiny tar-flecked specks. In many cases, these masses of webby material were spread along the inside wall of the vials and up against the para-film used to cover each bottle during the lyophilization process. After re-lyophilization, all material in each vial was stirred down from the vial walls, with a small metal spatula sterilized with ethanol and after several minutes wiped dry on a sterile wipe, to get a more homogenous substance. Even after stirring with the spatula, the material appeared to be a mix of tar specks and crystals. Remaining extracted and re-lyophilized samples were stored in a desiccation chamber at room temperature.

Should methanol extraction of micro-molecules be repeated in $M$. expansa, nitrogen drying time should be reduced to a few minutes followed by post extraction relyophilization. This should become part of the protocol. Lack of sufficient plant material, limits on access to equipment, and time tables affecting collaborators and benefactors, have caused repetition of extractions to be impractical to date.

\section{Cytotoxicity Testing of $M$. expansa}

For the cytotoxicity assay cells were cultured in MEME medium (Hyclone, Logan UT) modified with amphotericin B (Fungizone, $0.25 \mu \mathrm{g} / \mathrm{mL}$ ), 10\% fetal bovine serum (FBS), penicillin (100 units $/ \mathrm{mL})$ and streptomycin $(100 \mu \mathrm{g} / \mathrm{mL})$. Cells were grown in an atmosphere of $95 \%$ air and $5 \% \mathrm{CO}_{2}$ in a humidified incubator at $37^{\circ} \mathrm{C}$. Once cells reached a nearconfluent state, usually taking five or more days, they were trypsinized and split for sub-culture. At 60-70\% confluence, medium was changed and cells were used one day later for testing. Harvested cells were diluted for seeding into 96-well plates $(9500$ cells $/ 190 \mu \mathrm{L})$ with complete medium. Cells were then tested with the methanol extracted samples $(10 \mu \mathrm{L} /$ well in triplicate) at various concentrations of sample. Plates were incubated at $37^{\circ} \mathrm{C}$, in $5 \% \mathrm{CO}_{2}$, for three days. Twenty $\%$ trichloroacetic acid (TCA; $100 \mu \mathrm{L} /$ aliquot) was added to each well on the third day. Plates were then set for 30 minutes at $4^{\circ} \mathrm{C}$. Plates were next washed three times with tap water, and allowed to air dry overnight. After air-drying, $0.4 \%$ sulforhodamine B (SRB; $100 \mu \mathrm{L} /$ well) was added and the plates left at room temperature for $30 \mathrm{~min}$. Each well was then washed with $1 \%$ acetic acid and the plates were again allowed to air dry. Bound stain was solubilized with $10 \mathrm{mM}$ unbuffered Tris base (pH 10, $200 \mu \mathrm{L} /$ well).

\section{SI Results and Discussion}

Amino acid profiles were compared between those for $M$. expansa, and a variety of plant and other protein sources taken 
from the literature (Tables 1 and 2, SI Table 1). In addition, the percentage of CRDP for each $M$. expansa amino acid is given in a separate table (SI Table 2). As stated in Materials and Methods above, all profiles data is standardized to $\mathrm{g} / 100$ $\mathrm{g}$. There is also consideration in this section of the potential meaning of the uniformly negative results for the ethanol extractions (Table 3).

M. expansa Compared with Other Crops, Data from All Sources Analyzed 


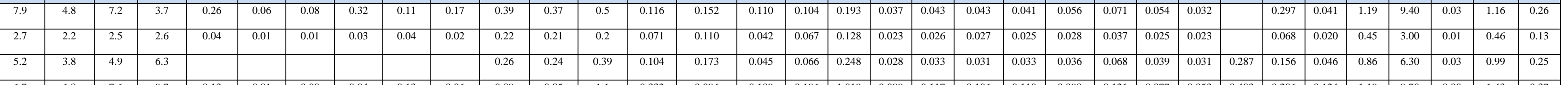

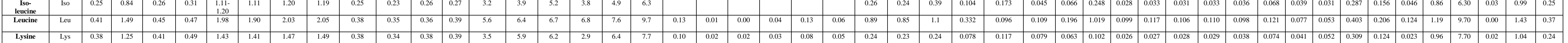

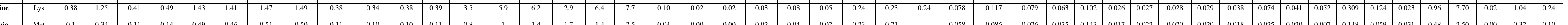

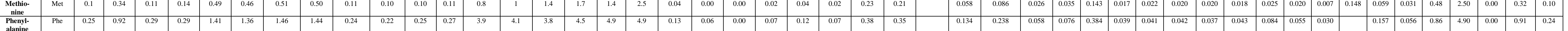

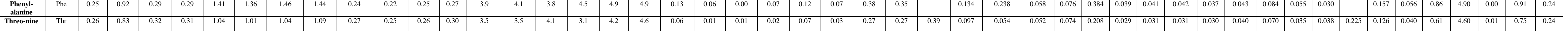

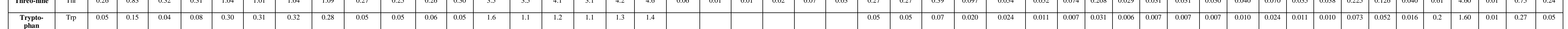

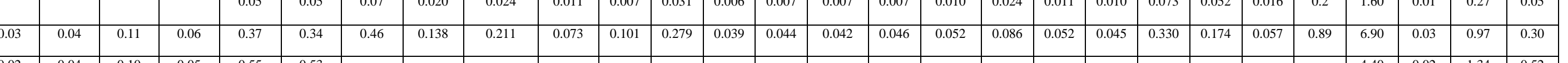

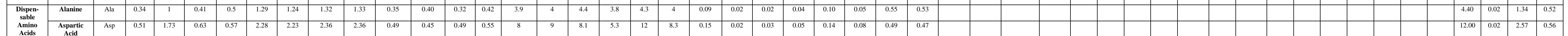

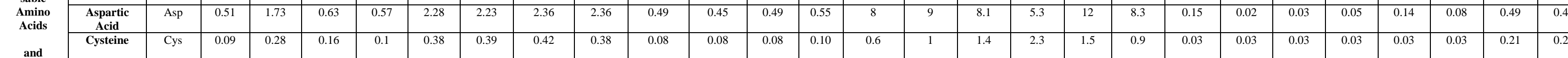

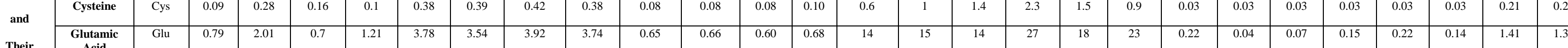

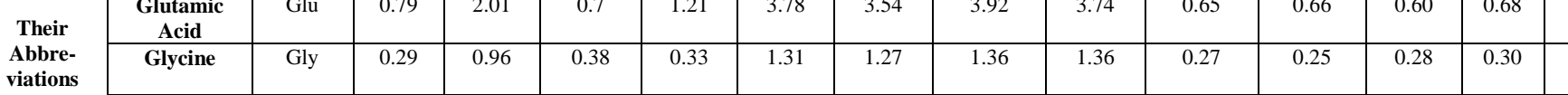

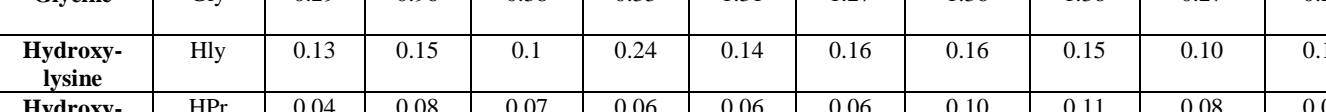

\begin{tabular}{cccccc|c|c|c|c|c|c|c|c|c|c|}
\hline $\begin{array}{c}\text { Hydroxy- } \\
\text { prorine }\end{array}$ & HPr & 0.04 & 0.08 & 0.07 & 0.06 & 0.06 & 0.06 & 0.10 & 0.11 & 0.08 & 0.06 & 0.07 & 0.08 \\
\hline
\end{tabular}

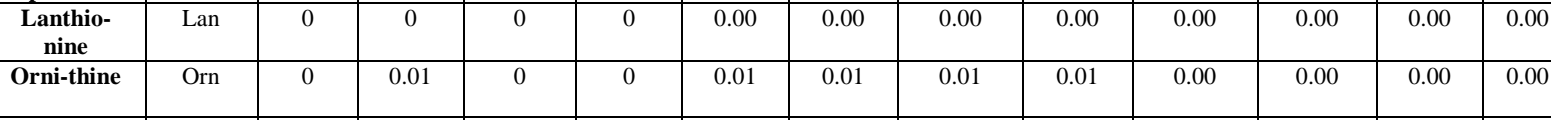

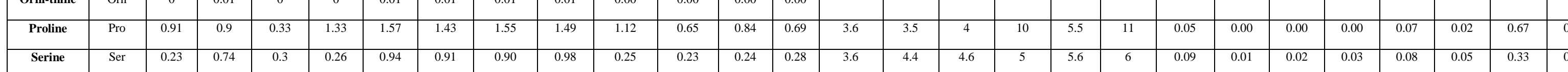

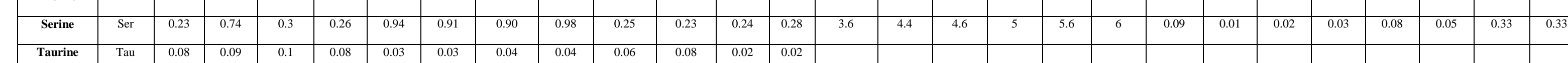

\section{Abbreviations:}

Grnhse $=$ Greenhous

hydrop $=$ hydrop
Var $=$ variety

Notes:

* Percentage N X 6.25.** Sample \#5 received January 7, 2010.

Results are expressed on an "as is" basis unless otherwise indicated.

It is not clear if the category '\% dry weight' i

Lit cited numbers match those in the pape Key to Lit Cited:

$6=$ Gutherie et al. 2004

$11=$ Socciet al. $1994 ;$
$11=$ Schlick et al. 1996

$38=$ Hawley et all 1946
$39=$ Lewis et al. 1982
$30=$.

$40=$ Nassar and Sousa 2007;
$41=$ USB/ US Pork Center of Excellence 2009 
Comparison of $M$. expansa to Other Crops-Indispensable Amino Acids

For percent ARG, with no value reported for egg [41], highest to lowest were hydroponic quinoa seeds 9.4; quinoa field seeds 7.9; soybean 7.2; wheat 4.8; quinoa hydroponic leaves 4.0 ; skim milk 3.7 ; var. ' $L$ ' leaf 1.28-1.36; egg [38] 1.19; var. ' $T$ ' leaf 0.99 ; corn2 0.5 ; corn gdhA+ 0.39; corn gdhA- 0.37; cassava root \#9 0.32 ; var. ' $T$ ' stem 0.27 ; var. ' $T$ ' root 0.26-0.28; cassava root \#ICB300-3 0.26; var. ' $L$ ' root 0.21-0.2; corn GrnYD 0.037; beet 0.032; flax 0.297; corn Glutmeal 0.193; cassava root \#Avg6 0.17; corns DDGHP 0.152 and DDGS 0.116; cassava root \# ICB-300Dp and corn Germ both 0.11; corn Glutfeed 0.104; cassava root \#4 0.08; alfalfa 0.071; cassava root \#10 0.06; corn Hom 0.056; Bar 0.054; corns GrnHN and GrnHO both 0.043; and corn GrnLP and millet both 0.041 .

For percent HIS, with no value reported for egg [41], highest to lowest were: hydroponic quinoa seeds 3.0 ; quinoa field seeds 2.7; skim milk 2.6; soybean 2.5; wheat 2.2; hydroponic quinoa leaves 1.2 ; var. ' $L$ ' leaf $0.53-0.57$; egg [38] 0.45; var. ' $T$ ' leaf 0.42 ; corns gdhA+ 0.22, gdhA- 0.21, and corn2 0.20 ; var. ' $T$ ' root $0.14-0.20$; var. ' $T$ ' stem 0.15 ; corn Glutmeal 0.128; var. ' $L$ ' root $0.12-0.13$; corns DDGHP 0.110 and DDGS 0.071; flax 0.068; corns Glutfeed 0.067 and Germ 0.042; cassava root \#ICB300-Dp 0.04; alfalfa 0.037 ; cassava root \#9 0.03; corns Hom 0.028, GrnHO 0.027, and GrnHN 0.026; corn GrnLP and Bar both 0.025; corn GrnYD and beet both 0.023 ; cassava root \#Avg6 and millet both 0.020; cassava root \#ICB300-3 0.024; and cassava roots \#10 and \#4 both 0.01 .

For percent ISO, with no values reported for any cassava roots, highest to lowest were: skim milk 6.30; quinoa field seeds 5.2; soybean 4.9; quinoa hydroponic seeds 3.9; wheat 3.8; quinoa hydroponic leaves 3.2; var. ' $L$ ' leaf 1.11-1.20; egg [38] 0.86; var. ' $T$ ' leaf 0.84 ; corn2 and Bar both 0.39; egg [41] 0.287; flax 0.156; alfalfa 0.068; millet 0.046; corn Hom 0.036; corns GrnHN and GrnLP both 0.033; corn GrnHO and beet both 0.031 ; corns GrnYD 0.028 and gdhA+ 0.26 ; var. ' $T$ ' root $0.25-0.31$; corns Glutmeal 0.248 and gdhA- 0.24; var. ' $L$ ' root 0.23-0.27; var. ' $T$ ' stem 0.26 and corns DDGHP 0.173, DDGS 0.104, Glutfeed 0.066, and Germ 0.045 .

For LEU highest to lowest were: skim milk 9.70; soybean 7.6; wheat 6.8; quinoa field seeds 6.7; quinoa hydroponic seeds 6.4 ; quinoa hydroponic leaves 5.6; var. ' $L$ ' leaf 1.90-2.05; var. ' $T$ ' leaf 1.49; egg [38] 1.19; corn2 1.10, corns Glutmeal 1.019, corn gdhA+ 0.89 and corn gdhA0.85 ; var. ' $T$ ' root $0.41-0.47$; var. ' $T$ ' stem 0.45 ; egg [41] 0.403 ; var. ' $L$ ' root $0.35-0.39$; corn DDGS 0.332 ; flax 0.2016; corn Glutfeed 0.196; cassava roots \#ICB300-3 and ICB300-Dp both 0.13 ; millet 0.124 ; alfalfa 0.121 ; corns GrnHN 0.117, GrnLP 0.110, Germ 0.109, GrnHO 0.106, GrnYD 0.099, Hom 0.098, and DDGHP 0.096; Bar 0.077; cassava root \#Avg6 0.06; beet 0.053 ; cassava root \#9 0.04; cassava root \#10 0.01; and cassava root \#40.00.

For percent LYS, highest to lowest were: skim milk 7.70; soybean 6.4; quinoa field seeds 6.2; quinoa hydroponic seeds 5.9; quinoa hydroponic leaves 3.5 ; wheat 2.9 ; var. ' $L$ ' leaf 1.41-1.49; var. ' $T$ ' leaf 1.25; egg [38] 0.96; var. ' $T$ ' root $0.38-0.49$; var. ' $T$ ' stem 0.41 ; var. ' $L$ ' root $0.34-0.39$; egg [41] 0.309; corns gdhA+ and corn2 both 0.24 , and gdhA0.23; flax 0.124; corns DDGHP 0.117 and Glutmeal 0.102; cassava root \#ICB300-3 0.10; cassava root \#ICB300-Dp 0.08; corns Germ 0.079 and DDGS 0.078; alfalfa 0.074; corn Glutfeed 0.063 ; beet 0.052 ; cassava root \#Avg6 0.05; Bar 0.041; corn Hom 0.038; cassava root \#9 0.03; corns GrnLP 0.029, GrnHO 0.028, GrnHN 0.027, and GrnYD 0.026 ; millet 0.023 ; and cassava roots \#10 and \#4 both 0.02 .

For percent MET, with no value reported for corn2, highest to lowest were: skim milk 2.50; wheat 1.7 ; quinoa field seeds and soybean both 1.4; hydroponic quinoa seeds 1.0 , hydroponic quinoa leaves 0.8 ; egg [38] 0.48 ; var. ' $L$ ' leaf $0.46-0.51$; var. ' $T$ ' leaf 0.34 ; corns gdhA+ 0.23 and gdhA- 0.21; egg [41] 0.148; corn Glutmeal 0.143; var. ' $T$ ' root $0.10-0.14$; var. ' $T$ ' stem 0.11 ; var. ' $L$ ' $\operatorname{root} 0.10-0.11$; corn DDGHP 0.086; flax 0.059; corn DDGS 0.058; cassava roots \#ICB300-3 and ICB300-Dp both 0.04; corn Glutfeed 0.035 ; flax 0.031 ; corn Germ 0.026; alfalfa 0.025; corn GrnHN 0.022; cassava roots \#9 and \#Avg6, and corns GrnHO and GrnLP, and Bar, all five 0.02; corns Hom 0.18 and GrnYD 0.017; beet 0.007 ; and cassava roots \#10 and \#4 both 0.00 .

For percent PHE, with no values reported for corn 2 or egg [41], highest to lowest were: soybean and skim milk both 4.90; wheat 4.50; hydroponic quinoa seeds 4.10; hydroponic quinoa leaves 3.90; quinoa field seeds 3.80; var. ' $L$ ' leaf 1.36-1.46; egg [38] 0.86; corns gdhA+ 0.38 and gdhA- 0.35; cassava root \#ICB300-Dp 0.12; cassava root \#ICB300-3 0.13; var. ' $T$ ' leaf 0.92; corns GrnHO 0.042, GrnHN 0.041, GrnYD 0.039, and Glutmeal 0.384; var. ' $T$ ' stem 0.29; var. ' $T$ ' root 0.25-0.29; corn DDGHP 0.238; var. ' $L$ ' root 0.22-0.27; flax 0.157; corn DDGS 0.134; alfalfa 0.084; corn Glutfeed 0.076; cassava roots \#9 and \#Avg6 both 0.07 ; cassava root \#10 0.06; corn Germ 0.058; millet 0.056; Bar 0.055; corns Hom 0.043 and GrnLP 0.037; beet 0.030 ; and cassava root \#4 0.00 .

For THR highest to lowest were: skim milk 4.60; soybean 4.2; quinoa field seeds 4.1; hydroponic quinoa leaves and seeds both 3.5; wheat 3.1; var. ' $L$ ' leaf 1.01-1.09; var. ' $T$ ' leaf 0.83 ; egg [38] 0.61 ; corn2 0.39 ; var. ' $T$ ' stem 0.32 ; corns gdhA+ and gdhA- both 0.27 ; var. ' $T$ ' root 0.26 0.31 ; var. ' $L$ ' root $0.25-0.30$; egg [41] 0.225; corn Glutmeal 0.208; flax 0.126; corns DDGS 0.097 and Glutfeed 0.074; cassava root \#ICB300-Dp and alfalfa both 0.07 ; cassava root \#ICB300-3 0.06; corns DDGHP 0.054 and Germ 0.052; corn Hom and millet both 0.040 ; beet 0.038; Bar 0.035; corns GrnHN and GrnHO both 0.031; cassava root \#Avg6 and corn GrnLP both 0.030; corn GrnYD 0.029; cassava root \#9 0.02 ; and cassava roots \#10 and \#4 both 0.01 .

For percent TRP, with no values reported for cassava roots, highest to lowest were: hydroponic quinoa leaves 1.60; skim milk 1.40; soybean 1.30; quinoa field seeds 1.20 ; hydroponic quinoa seeds and wheat both 1.1 ; var. ' $L$ ' leaf 0.28-0.32; egg [38] 0.20; var. ' $T$ ' leaf 0.15; egg [41] 0.073; corn2 0.07; flax 0.052; corns gdhA+ and gdhA- both 0.05 ; var. ' $T$ ' root $0.05-0.08$; var. ' $L$ ' root $0.05-0.06$; var. ' $T$ ' stem 0.04; corn Glutmeal 0.031; corn DDGHP and alfalfa both 
0.024; corn DDGS 0.02; millet 0.016; corn Germ and Bar both 0.011; corns GrnLP and Hom, and beet, all three 0.010; corns Glutfeed, GrnHN, GrnHO, and GrnLP, all four 0.007; and corn GrnYD 0.006 .

For VAL from highest to lowest were: skim milk 6.90; soybean 5.0; wheat 4.7; quinoa field seeds 4.6; hydroponic quinoa seeds 4.5 ; hydroponic quinoa leaves 4.0 ; var. ' $L$ ' leaf 1.34-1.44; var. ' $T$ ' leaf 1.01; corn2 0.46; corns gdhA+ 0.37 and gdhA- 0.34; egg [41] 0.330; var. ' $T$ ' root 0.32-0.38; var. ' $T$ ' stem 0.33 ; var. ' $L$ ' root $0.28-0.32$; corns Glutmeal 0.279 and DDGHP 0.211; flax 0.174; corn DDGS 0.138; cassava root \#ICB300-3 0.12; cassava root \#ICB300-Dp 0.11; corn Glutfeed 0.101; egg [38] 0.890; alfalfa 0.086; corn Germ 0.073; cassava root \#Avg6 0.06; millet 0.057; corn Hom and Bar both 0.052; corn GrnLP 0.046; beet 0.045; corns GrnHN 0.044 and GrnHO 0.042; cassava root \#9 0.04; corn GrnYD 0.039; and cassava roots \#10 and \#4 both 0.03 .

\section{Comparison of $M$. expansa to Other Crops-Totals}

For percent TOTP, with no values reported for any corn except corn2 and also not for alfalfa, Bar, beet, egg [41], flax or millet, highest to lowest were: var. ' $L$ ' leaf 22.84 24.43; var. ' $T$ ' leaf 16.8; egg [38] 7.69; var. ' $T$ ' root 5.987.76; var. ' $T$ ' stem 5.99; var. ' $L$ ' root 5.34-5.98; wheat 4.0; skim milk 3.4; soybean 2.9, quinoa field seeds 2.8, hydroponic quinoa seeds 2.0; hydroponic quinoa leaves 1.4 ; cassava root \#ICB300-3 1.65; cassava root \#ICB300-Dp 1.45; cassava root \#Avg6 0.94; cassava root \#9 0.92; and cassava roots \#10 and \#4 both 0.34 .

For percent CRDP, with no values reported for any cassava samples and not for corns gdhA+ and gdhA-, nor for egg [38], highest to lowest were: var. ' $L$ ' leaf 28.70-30.66; var. ' $T$ ' leaf 22.52 ; skim milk 9.9 ; var. ' $T$ ' $\operatorname{root} 8.94-13.91$; soybean 8.40; var. ' $L$ ' root 7.88-9.31; var. ' $T$ ' stem 8.78; wheat 7.6; hydroponic quinoa seeds 7.3 ; quinoa field seeds 6.9; hydroponic quinoa leaves 6.5; corn Glutmeal 6.02; egg [41] 4.70; corn DDGHP 4.18; flax 3.36; corns DDGS 2.74 and Glutfeed 2.15; alfalfa 1.70; corn Germ 1.48; Bar 1.13; millet 1.11; corn Hom 1.03 and corn2 0.96; corns GrnHN and GrnLP both 0.92 ; beet 0.86 ; and corns GrnHO 0.84 and GrnYD 0.83 .

\section{Cytotoxicity Screening with HT-29 Colon Cancer Cells}

Though disappointing from the standpoint of curing cancer, the results of the cell assay can be considered favorable preliminary food safety data, at least for nonvolatile micro-molecules in varieties ' $L$ ' and ' $T$ '. In addition, these results are limited to short season southern Illinois grown M. expansa [18]. Northern temperate growing seasons are only a few months long. Andean material is often grown from about nine months to two years, prior to harvest. Possibly, more mature and biennial plants begin to produce additional compounds, or do so in response to environmental stimuli not in effect during the growth experiments in southern Illinois.

Problems with the nitrogen drying of extracted material for the cytotoxicity assay, most likely resulted in loss of any active volatile compounds, if present. If the need and opportunity arise for future methanol extractions of $M$. expansa, a much shorter typical drying time under nitrogen should be followed by lyophilization in hopes of retaining volatile chemicals. It is unclear why it is difficult to dry the M. expansa samples. It may be the high amounts of calcium oxalate crystals, or the minute size of $M$. expansa starch molecules, interfere with drying. Possibly a clear oil gave the appearance of residual methanol in the samples.

There were limits on when methanol extractions could be done, due to availability of equipment and supplies for that purpose. There were also limits on when the extracts could be submitted for the cytotoxicology assay. Therefore, there has been no opportunity to date to repeat the extractions or cytotoxicity tests. There were problems with maintaining even temperatures during the extraction process as the rotary evaporator had a faulty temperature gauge. These issues are discussed in greater detail in Appendix D-1 of Kritzer Van Zant's dissertation [22]. Manual control of the water bath temperature was required when that temperature fluctuated. As extractions of individual samples lasted up to 15 hours without interruption, requiring continuous attention, there were several moments when temperatures briefly became high enough to potentially damage micro-molecules in at least two samples. In addition, the difficulty of drying the samples with nitrogen gas, and the long drying periods initially tried with that gas, may have caused the loss of volatile molecules. It must be considered that consistent negative results from the cytotoxicity assay are more believable under these limitations, than they would have been had any of them been positive. Despite these limitations, consistently negative cytotoxicity results indicate there is unlikely to be a nonvolatile micro-molecule toxin in short season southern Illinois grown varieties ' $L$ ' or ' $T$ '.

\section{SI Conclusions}

Fortunately, modern methods as well as traditional ones are available to address the high calcium oxalate load in $M$. expansa, and may prove valuable for other foods as well. Several methods may be of use in separating calcium oxalate crystals from the starch and protein in M. expansa. From our experience making the extractions, and from personal communication with Jorge Vivanco, a different solvent than methanol should be used if centrifuging is to be part of processing to remove the crystals, in order to maintain the integrity of the protein.

Though dispensable ornithine production was extremely low and undetected in the field grown plants, it is interesting that ornithine was detected in var. ' $T$ ' grown in the greenhouse. It may just be that the amount of ornithine produced in that sample was barely of sufficient quantity for the sensitivity of the amino acid profile assay to recognize it, while in other samples levels of ornithine produced were in amounts too low for recognition. Perhaps there is an epigenetic component to ornithine production. This could hold implications for production of other amino acids in $M$. expansa as well. M. expansa may hold additional value, for better understanding of the effects of differences in ploidy and/or epigenetics in real time, based on the crop's highly plastic morphology, and perhaps on its chemistry as well. 


\section{Acknowledgements}

Thank you to Jim Persinger, Bill Barthalomew, John Haddock, John Miller, and the Horticultural Research Center, all at SIU-C. Thank you also to Douglas Kinghorn at Oregon State University, Thomas P. Mawhinney at University of Missouri, and to Abraham Kritzer. Amino acid profile reports for each year were approved by Dr. Thomas P. Mawhinney, Director of Analytical Service at the Agricultural Experiment Station Chemical Laboratories, University of Missouri-Columbia.

\section{Author Contributions}

Ground preparation, planting and weeding of plots, lyophilization, methanol extractions and methanol removal, preparation and sending of samples for profiling and cytotoxicity assays, interpretation of the data, preparation of amino acid tables and writing were done by Miriam Kritzer Van Zant, who also made all arrangements for collaborations. Hee-byung Chai performed the cytotoxicity assay in Douglas Kinghorn's lab, and Dr. Chai also prepared Table 3. William J. Banz paid for the amino acid profiles. Gary Apgar assisted with selection of sources from the literature for amino acid profile comparisons to M. expansa. David Lightfoot assisted with lab space for extractions, access to sand plots and the greenhouse, advice and encouragement.

\section{References}

1. Popenoe H, King SR, J León J, Kalinowski LS (1989, 1990). Mauka. In: Vietmeyer ND (ed), Lost crops of the Incas; Little-known plants of the Andes with promise for worldwide cultivation. Washington DC: National Academies Press. pp. 74-81, 331.

Available at: https://www.nap.edu/read/1398/chapter/9

2. Sperling CR, King SR (1990) Andean tuber crops: worldwide potential. In: Janick J, Simon JE (eds), Advances in New Crops. Portland, OR: Timber Press. pp. 428-435. Available at:

https://hort.purdue.edu/newcrop/proceedings1990/V1428.html

3. Flores HE, Walker TS, Guimarães RL, Bais HP, Vivanco JM (2003) Andean root and tuber crops: underground rainbows. HortScience 38: 161-167. Available at:

http://hortsci.ashspublications.org/content/38/2/161.full. pdf + html

4. Ugent D, Ochoa C (2006) La etnobotánica del Perú: desde la prehistoria al presente Lima, Perú: Consejo Nacional de Ciencia, Tecnología e Innovación Tecnológica, CONCYTEC. 403 Pp.

5. Lappe' FM $(1991,1971)$ Diet for a Small Planet. NY, New York: Ballantine Books. Pp. 524.

6. Gutherie TA, Apgar GA, Griswold KE, Lindemann MD, Radcliffe JS, Jacobson BN (2004) Table 1: Statistically analyzed amino acid content (\%) of genetically modified $(\mathrm{gdhA}+)$ corn and similar nontransgenic (gdhA-) corn, in Nutritional value of a corn containing a glutamate dehydrogenase gene for growing pigs. J. Anim. Sci. 82: 1693-1698.
7. Young VR, Pellet PL (1985) Wheat proteins in relation to protein requirements and availability of amino acids. Am. J. Clin. Nutr. 41: 1077-1090. Available at: https://academic.oup.com/ajcn/article-

abstract/41/5/1077/4691707?redirectedFrom=fulltext

8. Young VR, Pellet PL (1994) Plant proteins in relation to human protein and amino acid nutrition. Am. J. Clin. Nutr. 59: 1203S-1212S.

9. Raven PH, Evert RF, and SE (2005) Biology of Plants. $7^{\text {th }}$ Edition. N.Y., New York: W.H. Freeman and Company. pp. 817.

10. Reeds PJ (2000) Criteria and significance of dietary protein sources in humans. J. Nutr. 130: 1835S-1840S.

11. Souci SW, Fachmann W, Kraut H (1994) Food Composition and Nutrition Tables. $5^{\text {th }}$ ed. Boca Raton, Florida: CRC Press. pp. 1088.

12. Schlick G, Bubenheim DL (1996) Quinoa: Candidate crop for NASA's controlled ecological life support systems. In: Janick J (ed), Progress in New Crops. Arlington, VA: ASHS Press. Pp. 632-640. Available at: https://hort.purdue.edu/newcrop/proceedings1996/V3632.html

13. Comino I, de Lourdes Moreno $M$, Real A, RodríguezHerrera A, Barro F, Sousa C (2013) The gluten- free diet: testing alternative cereals tolerated by celiac patients. Nutrients 5: 4250-4268. Available at: https://www.ncbi.nlm.nih.gov/pmc/articles/PMC382007 2/

14. WHO (World Health Organization) (2007) Protein and amino acid requirements in human nutrition; Report of a joint WHO/FAO/UNU expert consultation; WHO technical report series 935. Geneva, Switzerland: United Nations University. pp. 265. Available at: http://apps.who.int/iris/bitstream/handle/10665/43411/ WHO_TRS_935_eng.pdf?sequence=1\&isAllowed=y

15. Roca W, Izquierdo J (1998) Under-utilized Andean food crops: status and prospects of plant biotechnology for the conservation and sustainable agricultural use of genetic resources. Acta Hort. (ISHS) 457: 157-172. Available at: https://www.actahort.org/books/457/457_20.htm

16. Rea J (1992, 1994) Andean roots. In: HernándezBermejo JE, León J (eds), Neglected crops: 1492 from a different perspective. Andalusia, Spain: Botanical Garden of Córdoba (1992) Rome, Italy: FAO-UN (1994) pp 172-176. Available at: http://www.fao.org/docrep/018/t0646e/t0646e.pdf

17. Kritzer Van Zant M (2016) History of Mirabilis expansa (Ruiz and Pav.) Standl.; Growth and use in the Andes. Atlas J. of Bio. doi: 10.5147/ajb.2016.0138: 236-248.

18. Kritzer Van Zant M, Diesburg K, Lightfoot DA (2018) Mirabilis expansa growth, yield, and quality traits: First US field trials for an ancient, endangered, Andean crop. Atlas J. of Bio. 551:574.

19. Lightfoot DA (2008) Blue revolution brings risks and rewards, letter. Science 321: 771-772.

20. Wright KR, Zegarra AV, Lorah WL (1999) Ancient Machu Picchu drainage engineering. J. of Irrigation and Drainage Engineering 125: 360-369. Available at: https://ascelibrary.org/doi/10.1061/\%28ASCE\%290733 $-9437 \% 281999 \% 29125 \% 3 \mathrm{~A} 6 \% 28360 \% 29$ 
21. Zehetner F, Miller WP, West LT (2003) Pedogenesis of volcanic ash soils in Andean Ecuador. Soil Sci. Soc. Am. J. 67: 1797-1809. doi:10.2136/sssaj2003.1797. Available at: http://pdf.usaid.gov/pdf_docs/PNACU698.pdf

22. Kritzer Van Zant M (2016) Analysis and development of Mirabilis expansa (Ruiz and Pav.) Standl.; For potential as a new root crop outside the Andes (Doctoral Dissertation). ProQuest Dissertations and Theses. (Accession order no. 12694). doi: https://doi.org/10.5147/ajb.v0i0.174

23. Seminario Cunya J (1994) Chapter 26 Aspectos etnobotánicos y productivos del chago, miso o mauka (Mirabilis expansa (Ruíz y Pavón) Standley. In: Seminario Cunya J (ed), Raices Andinas contribuciones al conocimiento y a la capacitación; Chapter VI mauka (Mirabilis expansa). Cajamarca, Perú: Universidad Nacional de Cajamarca. Pp. 367-377.

24. Arbizu C, Tapia M (1994) Andean tubers. In: Hernándo Bermejo JE, León, J (eds), Neglected crops: 1492 from a different perspective; Plant production and protection series no. 26. Lima, Peru: FAO (1994) pp. 149-163. Available at:

http://www.fao.org/docrep/018/t0646e/t0646e.pdf

25. NIH (National Institutes of Health) (2011) PA-09-213: Calcium oxalate stone diseases. (R01); 2011. Available at:https://grants.nih.gov/grants/guide/pa-files/PA-09213.html

26. Turroni S, Vitali B, Bendazzoli C, Candela M, Gotti R, et al. (2007) Oxalate consumption by lactobacilli: evaluation of oxalyl-CoA decarboxylase and formylCoA transferase activity in Lactobacillus acidophilus. J. Appl. Microbiol.103: 1600-1609.

27. Turroni S, Bendazzoli C, Dipalo SCF, Candela M, Vitali B, et al. (2010) Oxalate-degrading activity in Bifidobacterium animalis subsp. lactis: impact of acidic conditions on the transcriptional levels of the oxalyl coenzyme A (CoA) decarboxylase and formyl-CoA transferase genes. Appl Environ Microbiol.76: 56095620.

28. Ranganathan $N$, Ranganathan $P$, Friedman EA, Joseph A, Delano B, Goldfarb DS, Tam P, Venketeshwer A, Rao AV, Anteyi E, Musso CG (2010) Pilot study of probiotic dietary supplementation for promoting healthy kidney function in patients with chronic kidney disease. Adv. Ther. 27: 634-647. Available at: http://www.academia.edu/2108877/Pilot_Study_of_Pro biotic_Dietary_Supplementation_for_Promoting_Healt hy_Kidney_Function_in_Patients_with_Chronic_Kidne y_Disease

29. Vivanco J M, Weitzel D, Flores HE (1997) Characterization of a major storage root protein isolated from the Andean root crop species Mirabilis expansa. In: Flores HE, Lynch JP, Eissenstat D (eds), Radical biology: advances and perspectives on the function of plant roots. Rockville, MD: American Society of Plant Physiologists. Pp. 454-457.

30. Vivanco JM, Savary BJ, Flores HE (1999)

Characterization of two novel Type I ribosomeinactivating proteins from the storage roots of the Andean crop species Mirabilis expansa. Plant Physiol. 119: $1447-1456$.
31. Vivanco JM, Salazar LF, Querci M (1999) Antiviral and antiviroid activity of MAP- containing extracts from Mirabilis jalapa roots. Plant Dis. 83: 1116-1121.

32. Vivanco JM, Flores HE (2000) Biosynthesis of ribosome inactivating proteins from callus and cell suspension cultures from Mirabilis expansa. Plant Cell Rep. 19: 1033-1039.

33. Vepachedu R, Bais HP, Vivanco JM (2003) Cloning, characterization and induction of MEC, a type I ribosome-inactivating protein from $M$. expansa. Planta 217: 498-506.

34. Vepachedu R, Park SW, Sharma N, Vivanco JM (2005) Bacterial expression and enzymatic activity analysis of $\mathrm{ME}_{1}$, a ribosome-inactivating protein from Mirabilis expansa. Protein Expres Purif 40: 142-151.

35. Jones WP, Kinghorn AD (2010) Chapter 13. Extraction of plant secondary metabolites. In: Sarker SD, Latif Z, Gray AI (eds), Methods in biotechnology; Natural products extraction vol. 20. $2^{\text {nd }}$ edition. Totowa, New Jersey: Humana Press Inc. Pp. 323-351.

36. Likhitwitayawuid $\mathrm{K}$, Angerhofer $\mathrm{CK}$, Cordell GA, Pezzuto JM, Ruangrungsi N (1993a) Cytotoxic and antimalarial bisbenzylisoquinolme alkaloids from Stephenia erecta. J. Nat.Prod. 56: 30-38.

37. Likhitwitayawuid K, Angerhofer CK, Chai H, Pezzuto JM, Cordell GA, Ruangrungsi N (1993b) Cytotoxic and antimalarial alkaloids from the tubers of Stephaniapierrei. J. Nat. Prod. 56: 1468-1478.

38. Hawley EE, Edwards LE, Clark LC,Murlin JR (1946) Biological value of proteins in relation to the essential amino acids which they contain: v. comparison of the average effect of ten single amino acids with extra egg protein as supplements to an egg diet. J. Nutr. 32: 613630.

39. Lewis AJ, Barnes MB, Grosbach DA, Peo Jr. ER (1982) Sequence in which the amino acids of corn (Zea mays) become limiting for growing rats. J. Nutr. 112: 782-788.

40. Nassar NMA, Sousa MV (2007) Amino acid profile in cassava and its interspecific hybrid. Genet. Mol. Res. 6: 192-197.

41. USB/US Pork Center of Excellence (2009) Table 17. Amino acid comparison of feed ingredients for swine (as-fed basis). In: U.S. Pork Center of Excellence (eds), National swine nutrition guide, version 1.2. Pp. 37, 320. 2010. Available at:

https://www.usporkcenter.org/product/national-swinenutrition-guide/

42. Horwitz W, Latimer GW (2006, 2011) AOAC official method 982.30 E(a,b,c). In: Horowitz W, Latimer GW (eds), Chapter 45.3.05. Official methods of analysis of $A O A C$ International.18 ${ }^{\text {th }}$ ed. revision 1. Gaithersburg, MD: AOAC International.

43. House JD, Neufeld J, Leson G (2010) Evaluating the quality of protein from hemp seed (Cannabis sativa L.) products through the use of the protein digestibilitycorrected amino acid score method. J. Agric. Food Chem. 58: 11801-11807.

44. CGIAR. Our strategy; cassava; origin and uses. No longer available at:

http://www.cgiar.org/our-strategy/cropfactsheets/cassava/ 
45. Nassar NMA, Marques, AO (2006) Cassava leaves as a source of protein. J. Agric. Environ 4: 187-189.
Citation: Kritzer Van Zant M, Banz WJ, Chai HB, Apgar G, Lightfoot DA (2019) Amino Acid Profiles and Cytotoxicity of Mirabilis expansa (Ruiz and Pav.) Standl.; Baseline Data for A Rare Indigenous Andean Crop. Adv Nutri and Food Sci: ANAFS126. 